\title{
The influence of the curing conditions of concrete on durability after freeze-thaw accelerated testing
}

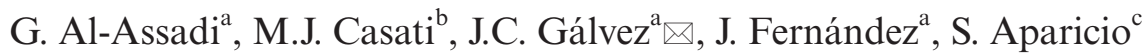 \\ a. E.T.S. de Ingenieros de Caminos, Canales y Puertos, Universidad Politécnica de Madrid, (Madrid, España) \\ b. E.T.S.I. Aeronáutica y del Espacio, Universidad Politécnica de Madrid, (Madrid, España) \\ c. Instituto de Tecnologías Físicas y de la Información "Leonardo Torres Quevedo", ITEFI, (CSIC), (Madrid, España) \\ $\triangle$ jaime.galvez@upm.es
}

\begin{abstract}
This work relates the curing conditions of concrete with the damage caused by rapid freeze-thaw cycles (ASTM C 666). The "potential" durability of concrete after testing is also studied. In countries with a continental climate, the curing of concrete in summer is performed under high-temperature and low-humidity conditions, and during the winter the concrete undergoes freezing and thawing. This paper shows the experimental results of the behaviour of concrete specimens cured under climatic summer conditions and then subjected to freeze-thaw cycles. Curing of the specimens includes conditions of good and bad practice in relation to wetting and protection of the concrete. Mechanical properties, cement hydration, volume and pore sizes, oxygen permeability, chloride diffusion and water penetration under pressure tests of the concrete are assessed. These tests were performed before and after the application of the freeze-thaw cycles. Statistical analysis of the correlation among variables is also included.
\end{abstract}

KEYWORDS: Concrete; Freezing/thawing; Hydration; Permeability; Curing

Citation/Citar como: Al-Assadi, G.; Casati, M.J.; Gálvez, J.C.; Fernández, J.; Aparicio, S. (2015) The influence of the curing conditions of concrete on durability after freeze-thaw accelerated testing. Mater. Construcc. 65 [320], e067 http://dx.doi.org/10.3989/mc.2015.06514.

RESUMEN: Influencia de las condiciones de curado del hormigón en su durabilidad tras los ensayos acelerados de ciclos hielo-deshielo. Este trabajo relaciona las condiciones de curado del hormigón con los daños causados por ciclos hielo-deshielo (ASTM C 666). Estudia la durabilidad "potencial" del hormigón dañado por este ensayo. En países con clima continental, el curado del hormigón en verano se realiza con alta temperatura y baja humedad, y durante el invierno sufre condiciones de hielo-deshielo. Se presentan los resultados experimentales de probetas de hormigón curadas bajo condiciones climáticas del verano y luego sometidas a ciclos hielodeshielo. El curado de las probetas incluye condiciones de buenas y malas prácticas en relación con el curado del hormigón. Se miden las propiedades mecánicas, grado de hidratación, volumen de poros y distribución de tamaños, permeabilidad al oxígeno, penetración de agua bajo presión y coeficiente de difusión de cloruros antes y después de la aplicación de los ciclos de hielo-deshielo. Se incluye un estudio estadístico para analizar la correlación entre las variables.

PALABRAS CLAVE: Hormigón; Hielo/deshielo; Hidratación; Permeabilidad; Curado

Copyright: (C) 2015 CSIC. This is an open-access article distributed under the terms of the Creative Commons Attribution-Non Commercial (by-nc) Spain 3.0 License. 


\section{INTRODUCTION}

The number of publications dealing with frost durability is extensive and this work does not seek to summarise all the contributions to this vast and complex subject (1-4). Concrete behaves well even under adverse weather conditions if it has been adequately designed, cast and cured. In countries with a continental climate, concrete is often cast in the summer months - under conditions of high temperature and low humidity - and is subject to freeze-thaw cycles during winter. This scenario can worsen if de-icing salts are added (5-7), such as the cases of the pillars and slabs of road bridges $(8,9)$.

A good curing process of concrete during the summer is essential for the durability of the material, especially under freezing conditions in the following winters $(10,11)$. The microstructure and hydration grade of the concrete are highly influenced by the curing conditions. In general terms, a good curing process creates a closer porous structure and higher physical and chemical resistance (12). It should be noted that for almost all types of concrete, resistance to internal cracking due to freeze and thaw cycles can only be achieved if the mixture contains an adequate system of entrained air voids $(7,13,14)$.

Several works have clearly indicated that the curing temperature can have a highly significant influence on concrete scaling resistance. However, in the laboratory the curing is generally performed by immersing samples in lime-saturated water or by placing them in a fog room, with both cases being quite close to saturated conditions. Surprisingly, the number of studies of the influence of the type of curing, combining high temperature and low humidity, on the scaling behaviour of the concrete remains extremely limited. While in certain cases the type of curing is found to have little influence $(15,16)$, in others concretes cured with a curing admixture appear to have an improved scaling resistance $(17,18)$.

Concrete cured under high temperatures, such as the steam-cured concrete coming from prefabrication plants, modifies the morphology of the hydrated silicates and shows a more crystalline and porous structure (19-24). This procedure has been found to be detrimental to the scaling resistance of the concrete. However, some authors (25-27) have found an improvement in the scaling resistance of the high-strength concrete when passing from $20^{\circ} \mathrm{C}$ to $60^{\circ} \mathrm{C}$ at early ages of the concrete.

The objective of this paper is to study the influence of the curing conditions of concrete when cast under summer conditions (high temperature and low humidity) in the internal deterioration and scaling resistance under freeze-thaw cycles (winter conditions). Since the curing conditions modify the microstructure of concrete, the "potential" durability is also studied after the rapid freezing-thawing tests, according to ASTM C 666 standard (28). This complementary aspect may be important, given that freeze-thawed damaged concrete is also exposed to aggressive environments, such as chloride ions or carbon dioxide. The freezing-thawing test, depending on the previous curing conditions of concrete, may modify the microstructure and the porous structure of the material, affecting the transport mechanisms (29).

In this work, conditions of good and bad practice curing conditions are studied. The effectiveness of using an air-entraining admixture is also examined. The experimental programme includes evaluation of the mechanical properties of the concrete, study of the cement hydration, measurement of the volume and pore sizes of the concrete, oxygen permeability, chloride diffusion and water penetration under pressure tests. These tests were performed before and after the application of the freeze-thaw cycles. The work includes a statistical study, based on Spearman's rank correlation coefficient, to analyse the possible correlation among variables. This analysis is needed for the correct interpretation of the experimental results.

Similar to previous papers focused on the frost resistance of concrete, this paper studies the influence of the curing conditions of the concrete in the freezing-thawing test, and the "potential" durability of the concrete after such a test. Analysis is performed for concrete with and without entrained air voids.

Whereas the following section examines the experimental programme, Section 3 shows the results. Discussion of the results is then presented in Section 4 , with Section 5 showing statistical analysis of the results. Finally, conclusions are presented in Section 6.

\section{EXPERIMENTAL PROGRAMME}

\subsection{Materials and specimens}

Four different concretes were tested, combining two compression strengths (C30 and C45) and either using or not an air-entrainment admixture. The mixes were cast by using the same cement: CEM I $42.5 \mathrm{R}$. The aggregate consisted of siliceous rolled with grade $0 / 5$ sand and 5/20 crushed limestone gravel. Whereas the fineness modulus was 2.71 for sand, it was 6.96 for gravel. A polycarboxylate superplasticiser was added $(0.6 \%$ of cement weight). An air-entrained agent was also added to two of the mixtures. The water/cement ratios were 0.5 and 0.4 for the $\mathrm{C} 30$ and C45 concretes, respectively. The water content of the admixtures was computed in the w/c ratio. Table 1 shows the compound composition of the cement. In Table 2, concrete mixes are given.

The concrete was mixed by using a vertical-axis planetary mixer with a capacity of 1001 . Fifteen cylindrical specimens of $150 \phi \times 300 \mathrm{~mm}$ height were cast for each concrete mix. 
TABLE 1. Compound composition of the cement

\begin{tabular}{lc}
\hline Compound & Weight percentage \\
\hline $\mathrm{C}_{3} \mathrm{~S}$ & 71.68 \\
$\mathrm{C}_{2} \mathrm{~S}$ & 7.96 \\
$\mathrm{C}_{3} \mathrm{~A}$ & 1.16 \\
$\mathrm{C}_{4} \mathrm{AF}$ & 14.53 \\
\hline
\end{tabular}

\subsection{Concrete curing}

All specimens were demoulded after 24 hours. They were subsequently stored in a climatic chamber at $30{ }^{\circ} \mathrm{C}$ and $37 \%$ relative humidity for 28 days. These temperature and humidity values represent the average environmental conditions of summer in central Spain. Under these conditions, two curing processes were performed. The so-called "wet curing" (W) was carried out daily, wetting the specimens inside the climatic chamber during the first week, as recommended by the Spanish Code of Structural Concrete (EHE-08) (30). The "dry curing" (D) was performed by avoiding the daily wetting of the specimens. The combination of the four types of concrete and the two curing conditions supplied eight different concretes with the following nomenclature: strength of concrete (30 $\mathrm{MPa}$ is C30 and $45 \mathrm{MPa}$ is $\mathrm{C} 45$ ) - percentage of air-entrained agent referring to the weight of cement $(0 \%$ is 00 , and $0.05 \%$ is 0.05 ) - type of curing (wet is $\mathrm{W}$ and dry is D). Table 3 shows the combination of these variables and the nomenclature of each cured concrete.

\subsection{Test procedures and methods}

\subsubsection{Mechanical properties}

In mechanical terms, three properties were measured: compressive strength (EN 12390-3 standard (31)), elasticity modulus (EN 12390-13 standard (32)) and tensile strength (EN 12390-6 standard (33)). The tests were performed before and after the freeze-thaw cycles.

\subsubsection{Freezing-thawing tests}

Six specimens for each type of concrete were tested according to freezing-thawing ASTM C 666 standard (28). One specimen of each type of concrete was stored at $20^{\circ} \mathrm{C}$ and $45-50 \%$ relative humidity for comparison.

The test was performed as follows: at the age of 28 days the specimens were immersed in water for four days by which saturation was ensured. Then, they were inserted in the climate chamber and subjected to 300 freeze-thaw cycles according to the temperature versus time diagram shown in Figure 1.

Every week, i.e. every 42 cycles, the length, weight and ultrasonic pulse velocity were measured in each specimen. The specimens were removed from the climatic chamber for measurement at a temperature of $10^{\circ} \mathrm{C}$. Upon completion of 300 freeze-thaw cycles, the modulus of elasticity, tensile and compressive strength was measured on each specimen. In accordance with the ASTM C 666 standard (28) the relative dynamic modulus of elasticity (RDME) was calculated [1]:

$$
P_{c}=\left(\frac{n_{1}}{n}\right)^{2} \times 100
$$

where: $P_{c}$ is the RDME, after $c$ freeze-thaw cycles (percentage), $n$ is the fundamental transverse frequency at 0 freeze-thaw cycles, and $n_{1}$ after $c$ cycles.

The durability factor is calculated as follows [2]:

$$
D F=\frac{P \times N}{M}
$$

where: $D F$ is the durability factor, $P$ is the RDME at $\mathrm{N}$ freeze-thaw cycles (percentage), $N$ is the number of cycles at which $P$ reaches the specified minimum

TABLE 2. Mix proportions $\left(\mathrm{kg} / \mathrm{m}^{3}\right)$

\begin{tabular}{lccccc}
\hline & \multicolumn{2}{c}{ Concrete C30 } & & \multicolumn{2}{c}{ Concrete C45 } \\
\cline { 2 - 3 } \cline { 5 - 5 } Component (kg/m $\mathbf{~}^{\mathbf{3}}$ ) & 381 & $\begin{array}{c}\text { Without air- } \\
\text { entrainment agent }\end{array}$ & $\begin{array}{c}\text { With air- } \\
\text { entrainment agent }\end{array}$ & $\begin{array}{c}\text { Without air- } \\
\text { entrainment agent }\end{array}$ & $\begin{array}{c}\text { With air- } \\
\text { entrainment agent }\end{array}$ \\
\hline Cement CEM I 42.5 R & 880 & 381 & & 400 & 400 \\
Siliceous sand (0/5) & 936 & 880 & & 769 & 769 \\
Crushed limestone gravel (5/20) & 4.77 & 936 & & 1167 & 1167 \\
Aggregate/cement & 0.94 & 4.77 & & 4.84 & 4.84 \\
Sand/gravel & 190 & 0.94 & & 0.66 & 0.66 \\
Water & 0.5 & 190 & & 160 & 160 \\
$\quad$ w/c & 2.3 & 0.5 & & 0.4 & 0.4 \\
Superplasticiser & 0 & 2.3 & & 5.0 & 5.0 \\
Air-entrainment agent & 0.2 & & 0 & 0.2 \\
\hline
\end{tabular}


TABLE 3. Nomenclature of the types of concrete with different curing processes

\begin{tabular}{lcccl}
\hline $\begin{array}{l}\text { Strength } \\
\text { (MPa) }\end{array}$ & $\begin{array}{c}\text { Air-entrainment } \\
\text { agent }\end{array}$ & $\begin{array}{c}\text { Type of } \\
\text { curing }\end{array}$ & Mixture & Designation \\
\hline 30 & No & wet & 1 & C30-00-W \\
& Yes & & 2 & C30-0.05-W \\
& No & dry & 3 & C30-00-D \\
& Yes & & 4 & C30-0.05-D \\
45 & No & wet & 5 & C45-00-W \\
& Yes & & 6 & C45-0.05-W \\
& No & dry & 7 & C45-00-D \\
& Yes & & 8 & C45-0.05-D \\
& & & & \\
\hline
\end{tabular}

value for discontinuing the test or the specified number of cycles at which the exposure is to be terminated, whichever is less, and $M$ the specified number of cycles at which the exposure is to be terminated.

\subsubsection{Physicochemical tests}

Physicochemical tests were performed in order to study the durability of concrete before and after freezing-thawing tests. Parameters concerning transport mechanisms in concrete were analysed. Mercury intrusion porosimetry, oxygen permeability, chloride diffusion and water penetration tests were performed. In addition, differential thermal analysis (DTA) and thermal gravimetric analysis (TG) were performed to study the hydration of the cement during the testing period.

Mercury intrusion porosimetry (MIP) tests were performed with a Micromeritics porosimeter, Autopore IV 9500 model, which reached a pressure of $228 \mathrm{MPa}$, and measured the diameter of pores from $0.006 \mu \mathrm{m}$ to $175 \mu \mathrm{m}$. The ASTM D4404 standard (34) was adopted. The weight of the sample was

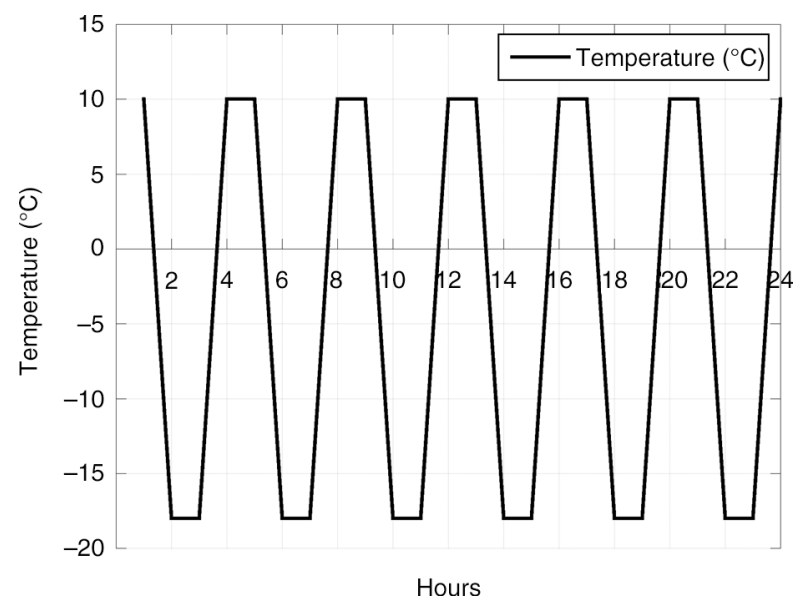

FIgURE 1. Freeze-thaw cycles used.
$3.5 \mathrm{~g} \pm 0.3 \mathrm{~g}$. The specimen was dried at $40{ }^{\circ} \mathrm{C}$ and degasified. For modelling, the pores were idealised as cylindrical channels, and the Washburn-Laplace law adopted to relate the mercury pressure with the radius of the pore, as equation [3] shows:

$$
p=\frac{-4 \gamma \cos \theta}{d}
$$

where: $\gamma$ is the surface tension, $\theta$ the contact angle, $d$ the pore diameter and $p$ the pressure required for mercury to penetrate into the pore.

The samples were obtained from cylindrical slices placed at $5 \mathrm{~cm}$ from the base of the specimens. In the case of the tests after freeze-thaw cycles, four samples were obtained and tested; these were extracted at different distances from the circumferential face of the specimen in the radial direction. Figure 2 shows a sketch of the specimen with the slices for the various tests.

The oxygen permeability tests were conducted according to RILEM-TC 116-PCD (35) and CEMBUREAU (36) recommendations. Tests were performed with two cylindrical slides $(\phi 150 \mathrm{~mm}$ $50 \mathrm{~mm}$ in thickness) cut from the bottom and upper parts of the specimen (see Figure 2). The flow of oxygen through concrete slides was measured at steady state against the test pressure and the material

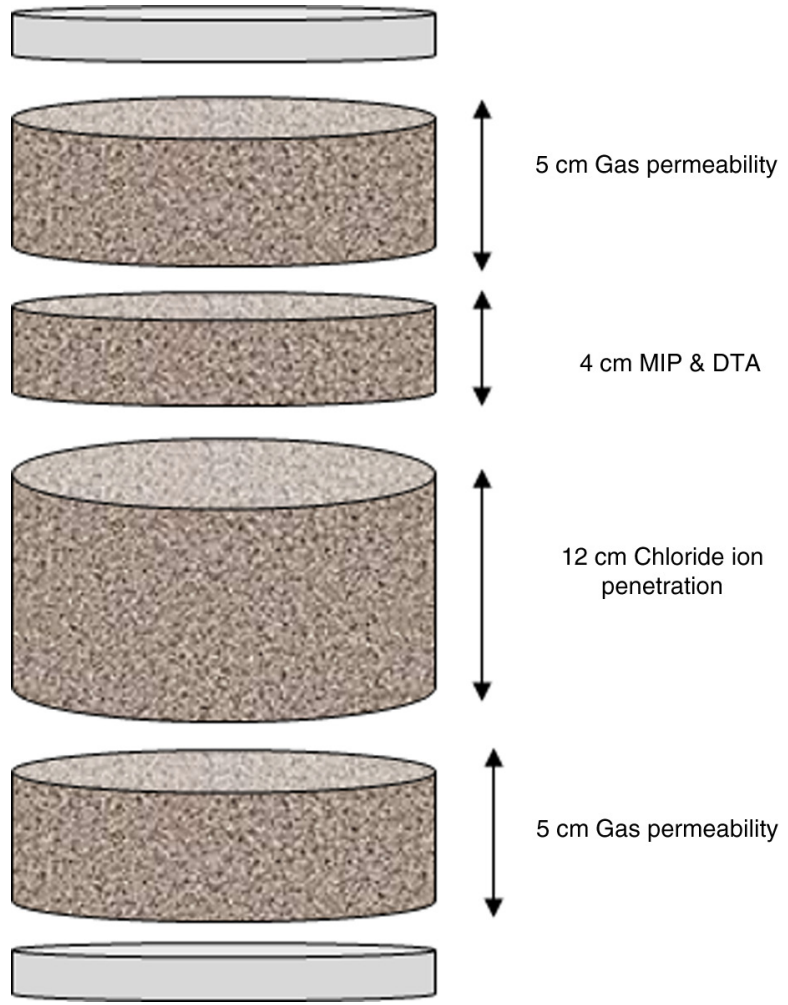

FiguRE 2. Sketch of the slices for different tests obtained from a cylindrical specimen. 
saturation rate. The apparent coefficient of permeability, $K_{A}$, was calculated for laminar flow of a compressible viscous fluid through a porous material from the Hagen-Poiseuille relationship [4]:

$$
K_{A}=\frac{2 Q p_{a t m} L \mu}{A\left(p^{2}-p_{a t m}^{2}\right)}
$$

where: $Q$ is the measured oxygen flow $\left(\mathrm{m}^{3} / \mathrm{s}\right), \mu$ the dynamic viscosity of the oxygen $\left(\mathrm{Ns} / \mathrm{m}^{2}\right), L$ the thickness of the sample $(\mathrm{m}), p_{\text {atm }}$ the atmospheric pressure $\left(\mathrm{N} / \mathrm{m}^{2}\right), A$ the cross-sectional area of the sample $\left(\mathrm{m}^{2}\right)$ pore diameter and $p$ the absolute pressure applied $\left(\mathrm{N} / \mathrm{m}^{2}\right)$.

A chloride diffusion test was performed with cylindrical $150 \phi \times 300 \mathrm{~mm}$ height samples, in accordance with the ASTM C1543 standard (37). This test was carried out in saturated material, under unidirectional diffusion (waterproofing the vertical face and bottom base of the cylinder) in an aggressive solution $(\mathrm{NaCl}$ concentration of $3 \%$ in deonised water) at $20{ }^{\circ} \mathrm{C}$. Measurement of the chloride concentration inside the specimen was performed down to the depth of $30 \mathrm{~mm}$, with intervals of $6 \mathrm{~mm}$. The UNE 112-010 Spanish standard (38) was adopted for measurement of the chloride concentration. The effective diffusion coefficient is calculated according the solution of Flick's second law [5]:

$$
C(x, t)=C_{s}-\left(C_{s}-C_{i}\right)\left(\operatorname{erf}\left[\frac{x}{\sqrt{4\left(D_{e} t\right)}}\right]\right)
$$

where, $C(x, t)$ is the chloride content at $x$ depth and $t$ time (percentage of weight), $x$ the depth (m), $t$ the time (s), $C_{s}$ the chloride content at the concrete surface (percentage of weight), $C_{i}$ the initial chloride content (percentage of weight), erf the error function and $D_{e}$ the effective chloride diffusion coefficient $\left(\mathrm{m}^{2} / \mathrm{s}\right)$.

Water penetration under a pressure test was performed with cylindrical $15 \phi \times 30 \mathrm{~cm}$ height samples, in accordance with the EN 12390-8 standard (39). Water applied pressure was $500 \mathrm{kPa}$ with a duration of three days. Then the sample was split and the depth profile of water within the split specimen measured.

A TG/DTA analysis was performed to study the hydration of the cement. The STA 791 device was used. The specimen was heated to a temperature of $1000{ }^{\circ} \mathrm{C}$, with a velocity of $10^{\circ} \mathrm{C} / \mathrm{min}$. The reference material was $\alpha-\mathrm{Al}_{2} \mathrm{O}_{3}$, heated to $1200^{\circ} \mathrm{C}$. The tests were carried out in $\mathrm{N}_{2}$ atmosphere with a flow of $80 \mathrm{ml} / \mathrm{min}$. Results, in accordance with the ASTM E1131 standard (40), were obtained when the concrete life was at 28,90 and 365 days.

\section{RESULTS}

\subsection{Results of the fresh concrete}

Table 4 shows the results of slump test (ASTM C 143 standard (41)) and the air content in the fresh concrete.

\subsection{Mechanical properties of concrete before and after freezing-thawing tests}

Figures 3, 4 and 5 show the results for the compressive strength, modulus of elasticity and tensile strength for the specimens before and after the freeze-thaw cycles.

\subsection{Results of freezing-thawing tests}

Figure 6 shows the evolution of the RDME under freeze-thaw testing for the $\mathrm{C} 30$ and $\mathrm{C} 45$ concretes. Figure 7 and Figure 8 show analogous results for length and weight variation of the specimens during the freeze-thaw cycles.

\subsection{Physicochemical properties}

Figure 9 compares the total porosity of the MIP tests for the concretes before and after freezethaw cycles. Figures 10 to 13 show the logarithmic differential intrusion volume and the cumulative intruded pore volume for the tested specimens. The shown curves for the specimens after freezethaw cycles are the mean value obtained from four points placed at different depths, measured in a radial direction.

Figure 14 shows the mean value of the depth water penetration for the specimens after water penetration under pressure tests.

Figure 15 shows the values of the effective coefficient of chloride diffusion of the concrete specimens before and after freeze-thaw cycles. Figure 16 shows the chloride profile in the tested concrete specimens. The presented profiles are the mean value of two slides from the same specimen, obtained from the bottom and upper parts of the specimen.

Figure 17 shows the apparent coefficient of oxygen permeability. This figure shows the mean value of two slides (upper and bottom part) from the same specimen.

TABLE 4. Results of the fresh concrete tests: slump and air content

\begin{tabular}{lcc}
\hline Designation & Slump (cm) & Air content (\%) \\
\hline C30-00-W/C30-00-D & 3 & 3.6 \\
C30-0.05-W/C30-0.05-D & 14 & 6.85 \\
C45-00-W/C45-00-D & 21 & 3.75 \\
C45-0.05-W/C45-0.05-D & 22.5 & 10.1 \\
\hline
\end{tabular}




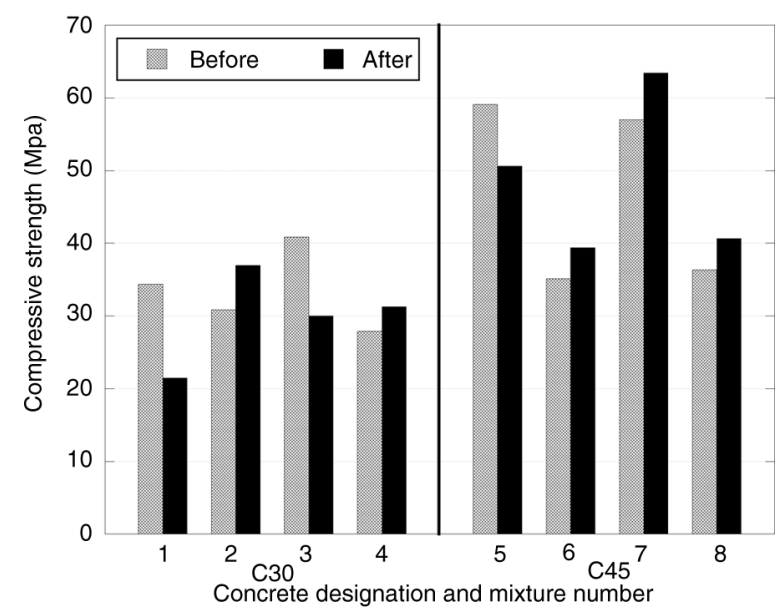

Figure 3. Compressive strength of the concrete before and after freeze-thaw cycles.

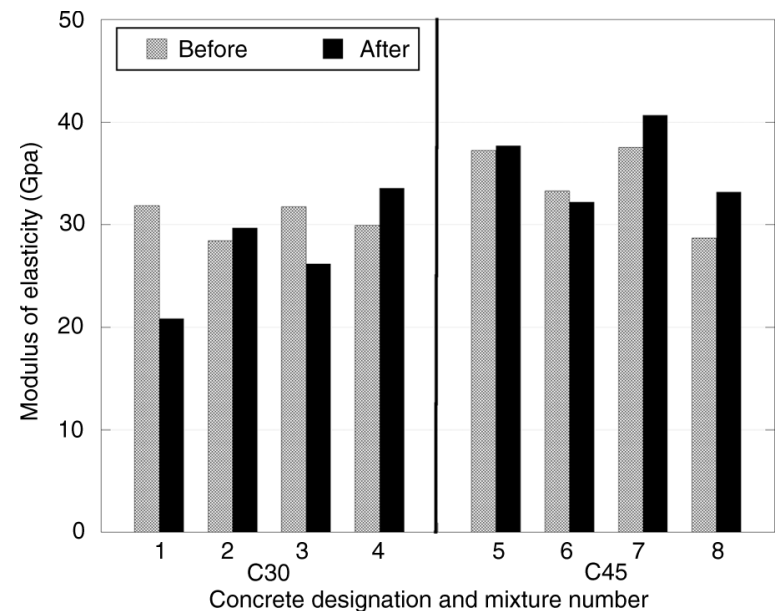

Figure 4. Modulus of elasticity of the concrete before and after freeze-thaw cycles.

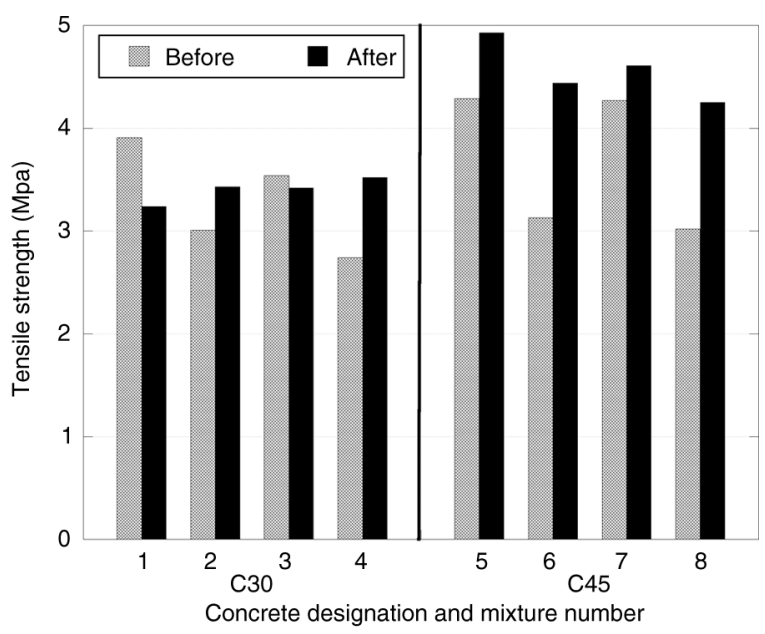

FIGURE 5. Tensile strength of the concrete before and after freeze-thaw cycles.

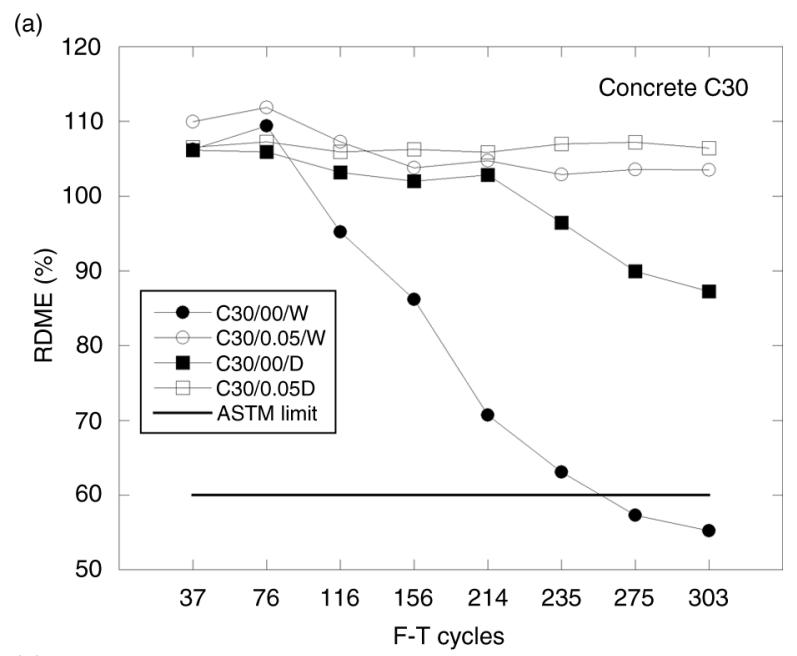

(b)

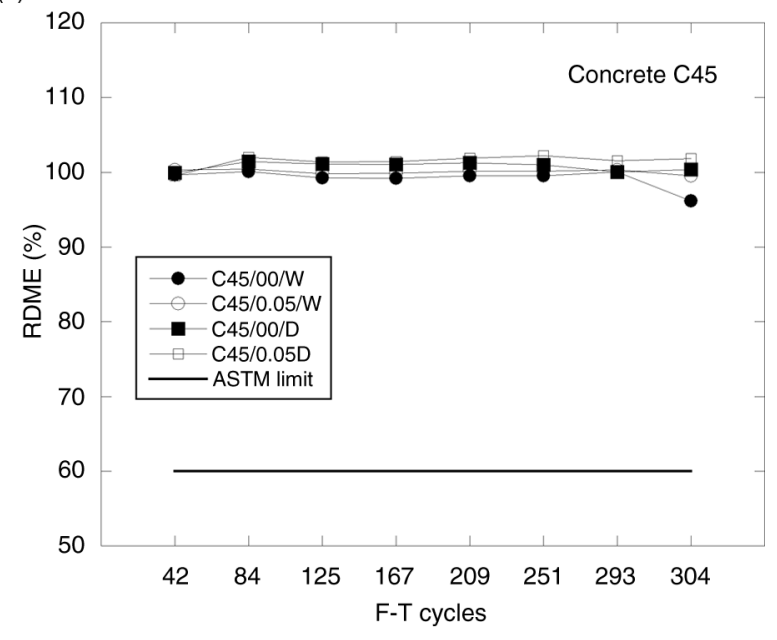

FIGURE 6. RDME evolution under freeze-thaw cycles: a) C30, b) C45.

Figure 18 ( $\mathrm{a}$ and $\mathrm{b}$ ) includes the hydration level of the concrete specimens at 28, 90 and 365 days.

\section{DISCUSSION}

\subsection{Mechanical properties of concrete before and after freeze-thaw cycles}

As a rule, air entrainment increased concrete porosity and reduced its compressive and tensile strength (see Figures 3 to 5).

In the absence of the air-entraining admixture, the $\mathrm{C} 30$ specimens showed poorer mechanical performance after the freeze-thaw cycle, while the C45 samples did not. Entrained air is, however, known to strengthen concrete resistance to freeze-thaw cycles. In this study, even the mechanical properties appeared to show improvement, most likely due to the greater age of the specimens (approximately 90 days) as well as their higher freeze-thaw resistance. 

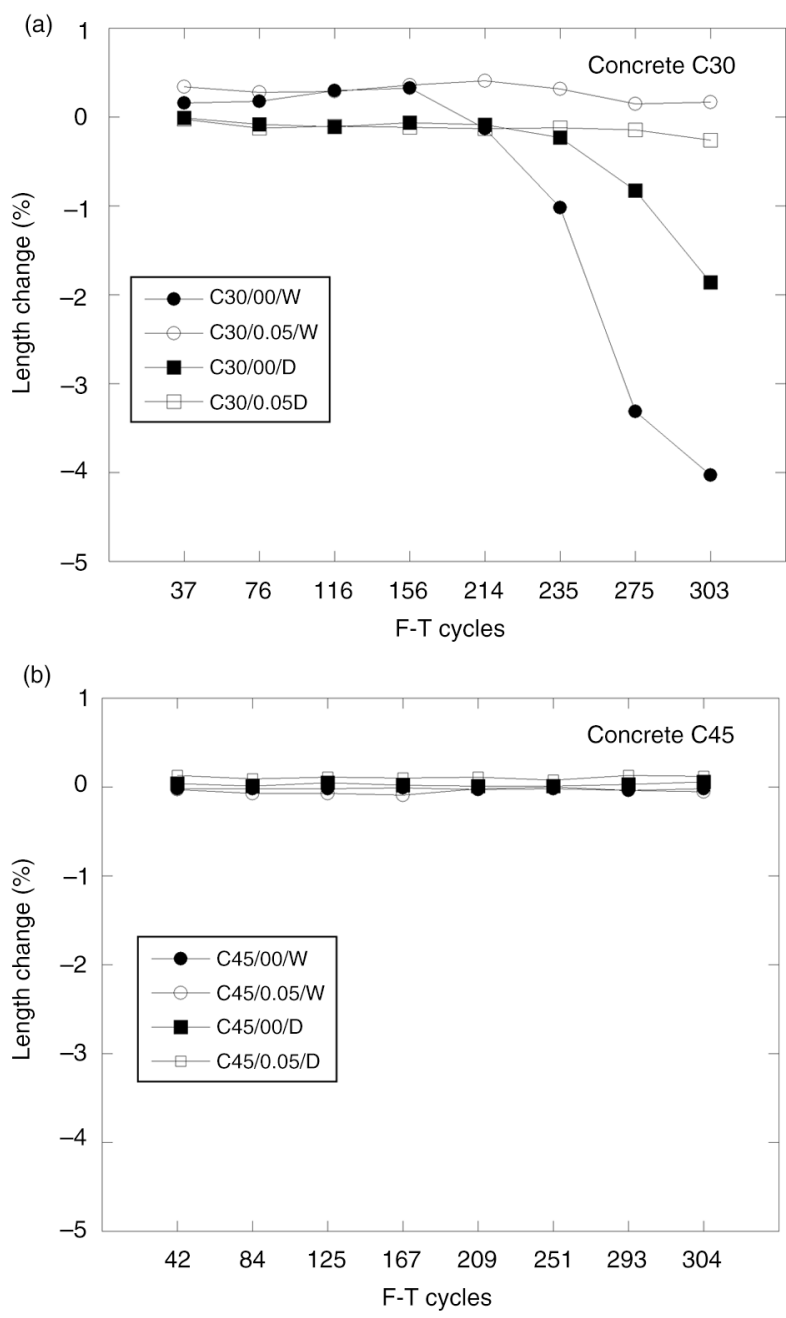

FIGURE 7. Length variation of the concrete specimens under freeze-thaw cycles: a) C30, b) C45.

\subsection{Non-destructive testing during freeze-thaw cycles}

As Figures 6 to 8 show, in the absence of the airentraining admixture, the decline in weight, specimen length and RDME intensified with the increase in the number of cycles. The concretes that contain the admixture, by contrast, exhibited practically no obvious change in weight, RDME or length during the cycles, even though such changes would normally be expected in this type of test.

While the ASTM C666 standard (28) does not use change in weight as a failure criterion, weight loss during the freeze-thaw cycles is a sign of concrete scaling, such as that observed in C30-00-W (Figure 8).

The decline in RDME values, denoting a decrease in ultrasound velocity, showed that in concrete with insufficient entrained air each freeze-thaw cycle generated cracks. Since the waves must follow a longer path in damaged concrete, their velocity decreases and the
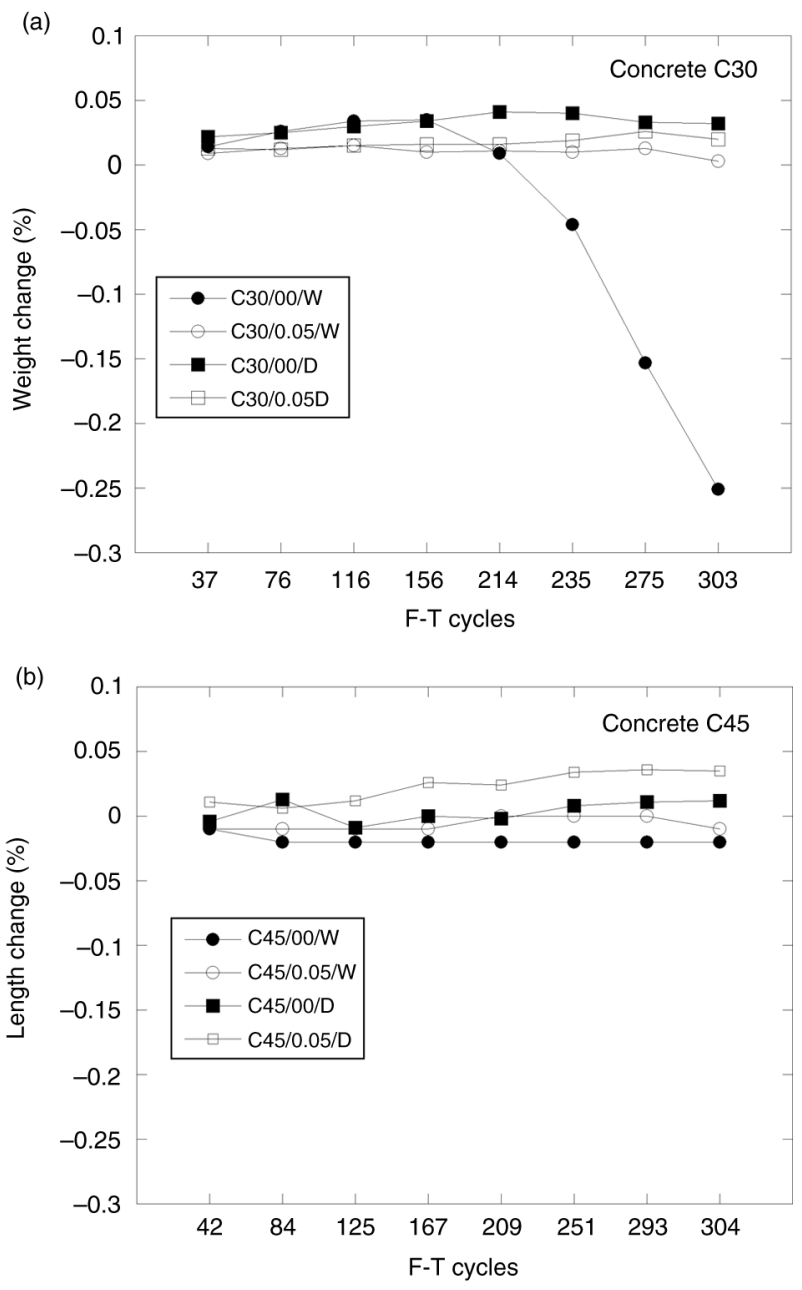

FIGURE 8. Weight variation of the concrete specimens under freeze-thaw cycles: a) C30, b) C45.

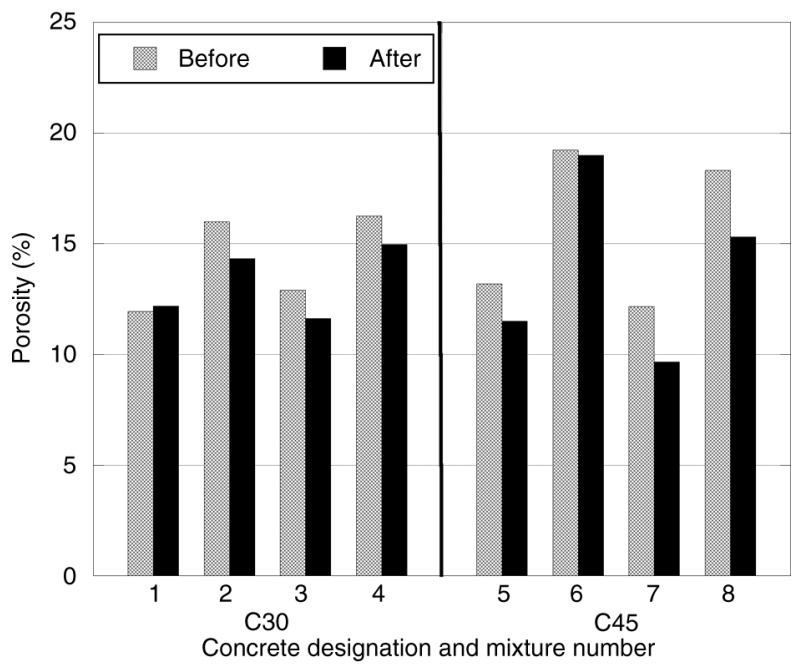

FIgURE 9. Total porosity of MIP tests before and after freezing-thawing test. 

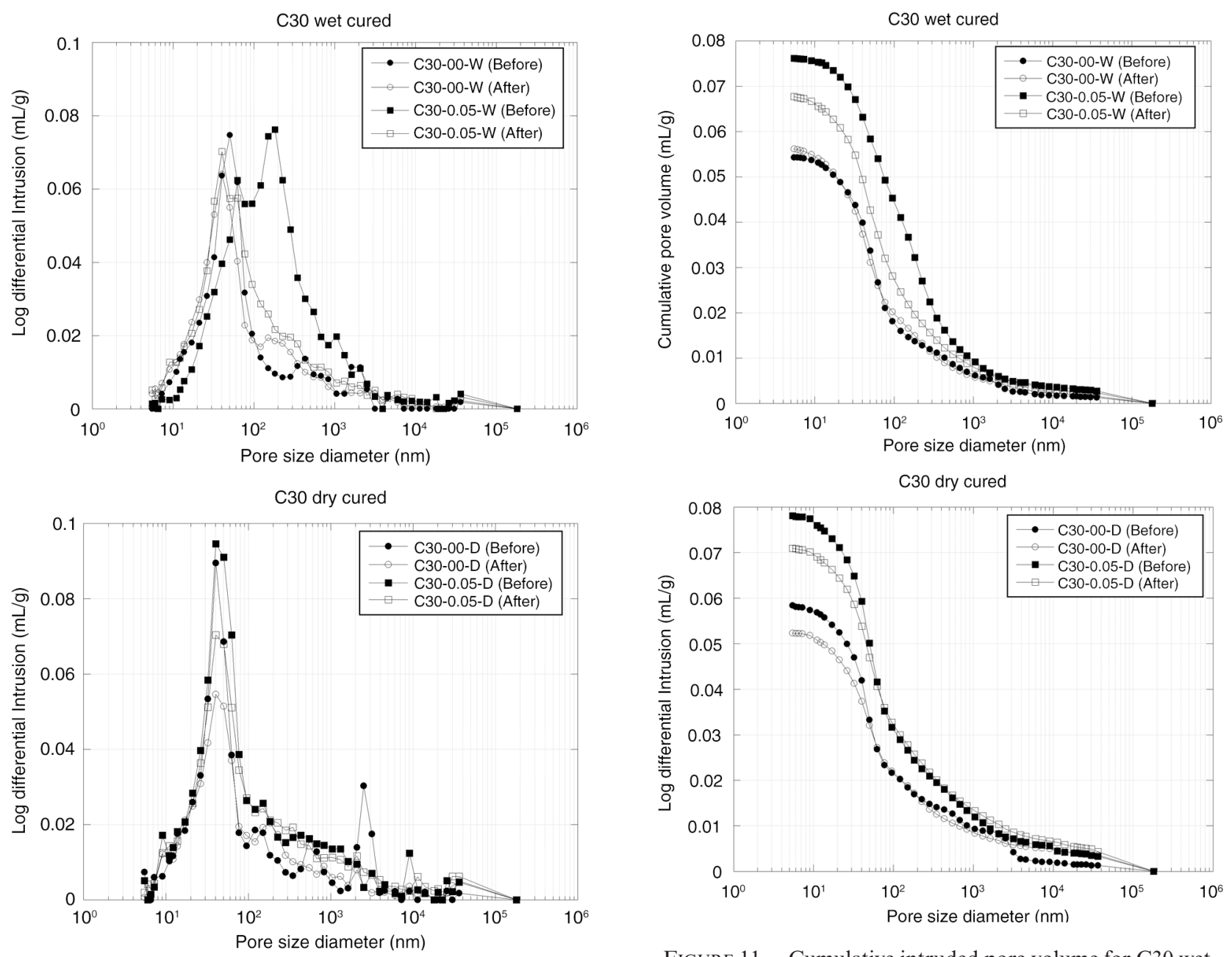

Figure 10. Distribution of pore diameter for $\mathrm{C} 30$ wet and dry cured (before and after freezing-thawing test).

waves themselves may be attenuated to such a point that they may fail to pass completely through the concrete. These findings, along with the weight and length data, confirmed the existence of post-cycle damage in the specimens, as predicted.

\subsection{Durability tests before and after freeze-thaw cycles}

The MIP findings revealed greater porosity in the wet- than in the dry-cured concrete after the cycles (see Figures 9 to 13). The explanation is to be found in the low relative humidity and high temperature curing conditions, which delayed cement hydration. Hydration continued during the freezethaw cycles in the moist chamber, though in the case of relative humidity being $98 \%$ the percentage of pores decreased. According to the results obtained for all the mixes, with the exception of C30-00-W where the variation was small, porosity declined after the freeze-thaw cycles by around

Figure 11. Cumulative intruded pore volume for $\mathrm{C} 30$ wet and dry cured (before and after freezing-thawing test).

$10 \%$ in concrete $\mathrm{C} 30$ and $15 \%$ in concrete $\mathrm{C} 45$. These values were unaffected by the inclusion of an air-entraining admixture. Table 5 shows the measured porosity after cycles at four distances from the surface (Figure 19). In all cases differences in the porosity values were found.

Should the decline in performance induced by exposure to the freeze-thaw cycles be the sole reason for the microstructural variations, the pore size distribution would be expected to change after the cycles: the peak representing the predominant size on the distribution curve should shift toward a greater diameter. As figures 10 to 13 show, however, this was not always the case. In some specimens the opposite was observed, with a significant increase in the smaller pores being observed after the freezethaw cycles. This may be because the hydration process, initially detained, re-commenced when the samples were water-saturated prior to the freezethaw cycles. This would mean that the initial water content in the concrete was insufficient to prevent 

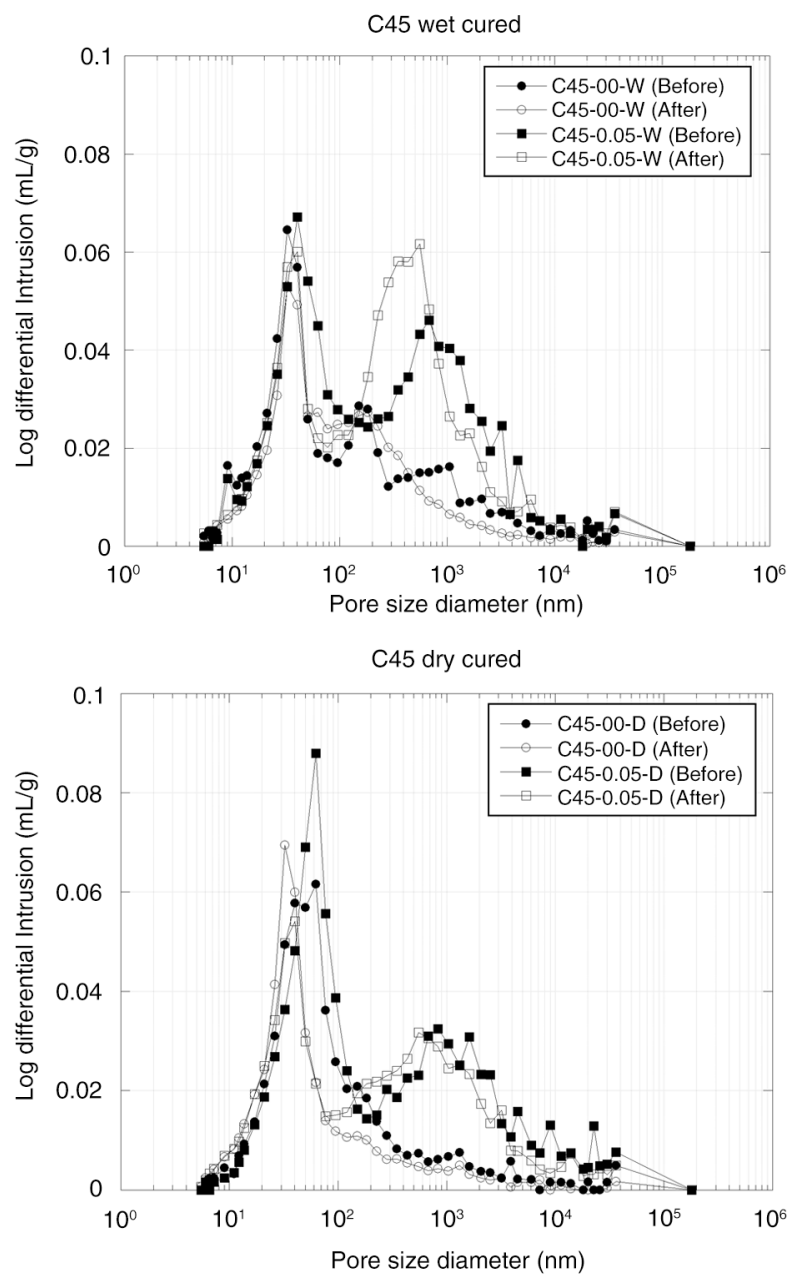

FIGURE 12. Distribution of pore diameter for $\mathrm{C} 45$ wet and dry cured (before and after freezing-thawing test).

self-desiccation and significant rehydration took place in some specimens.

The data on the penetration depth of water under pressure (Figure 14) showed that both concretes appeared to perform better when an air-entraining admixture was included in the mix. Both admixturefree concretes appeared to perform better when dry- than wet-cured. These findings also showed that all the concretes met the Spanish Code of Structural Concrete (EHE-08) (30) water-resistance requirements.

The chloride diffusion results for all the wetcured concretes (Figure 15 and Figure 16) showed a higher chloride content in the outer few centimetres after than before the cycles. Consequently, the initial curing conditions had a substantial impact on chloride ion penetration during early exposure to a chloride environment. After longer exposure periods, the effect of initial curing on chloride ion penetration was insignificant (42).
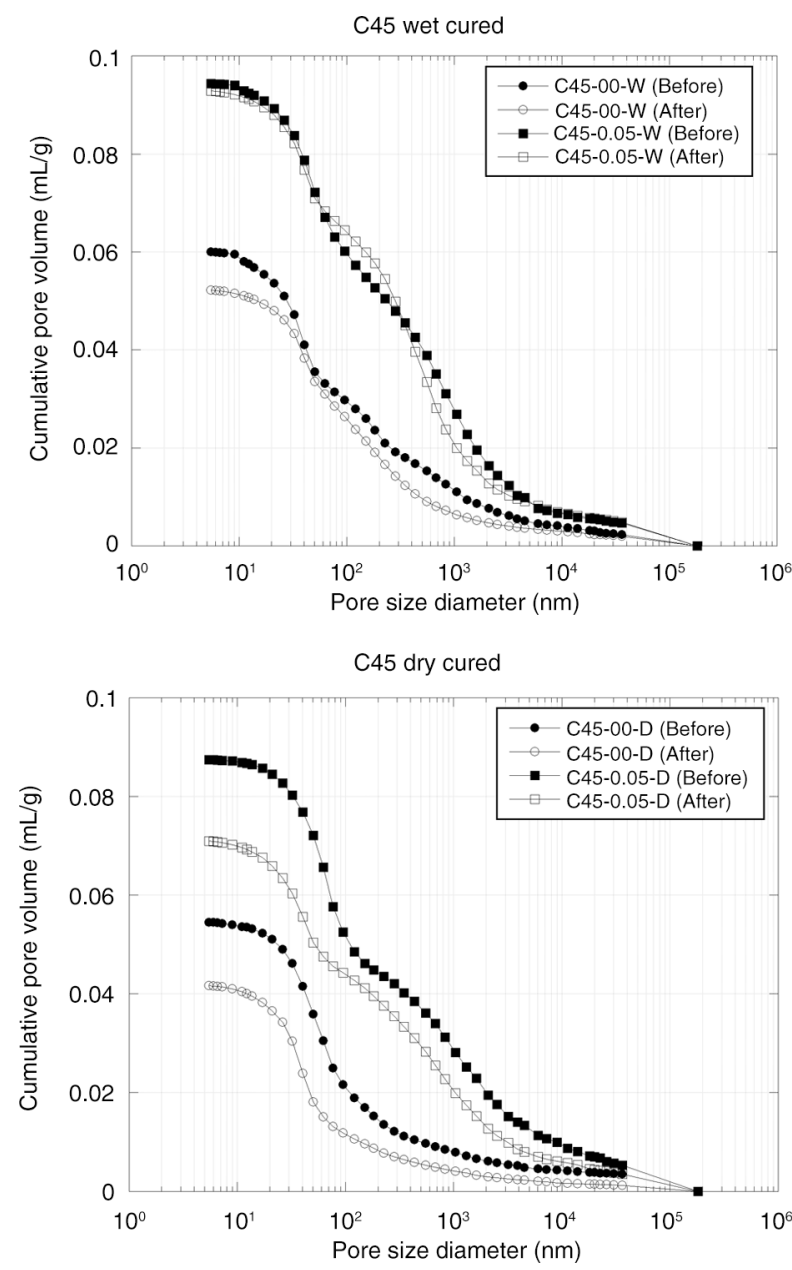

FIGURE 13. Cumulative intruded pore volume for $\mathrm{C} 45$ wet and dry cured (before and after freezing-thawing test).

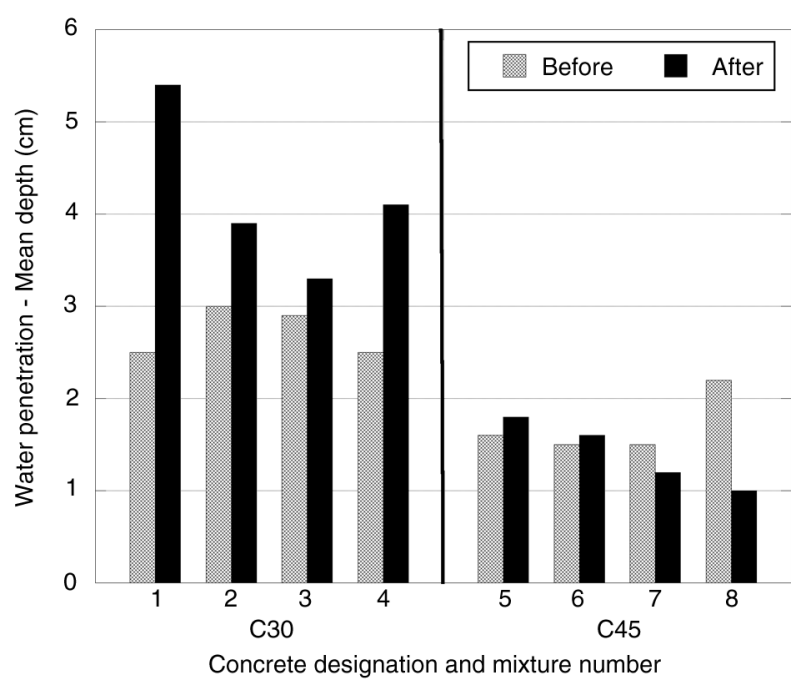

FIGURE 14. Depth of water penetration of concretes after water penetration under pressure test. 


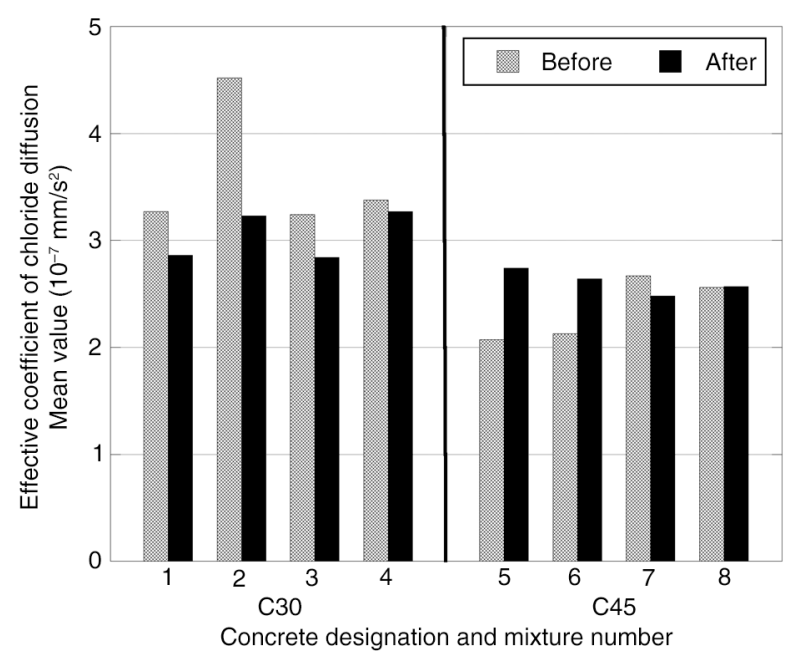

FIGURE 15. Effective coefficient of chloride diffusion of concrete (before and after freezing-thawing test).

The gas permeability constant before the freezingthawing test (see Figure 17) shows values in accordance with the porosity assessed by MIP (see Figure 9), with the values of C30 being greater than the ones of C45. The observations explained above for MIP findings may be extended to the gas permeability results. Since the gas permeability test assesses the "connected porosity", the lower values of the gas permeability constant for $\mathrm{C} 45$, in comparison with $\mathrm{C} 30$, are in agreement with a closer porosity induced by a higher content of cement. The gas permeability constant declined after the freezingthawing test, in accordance with the hydration that continued during the freeze-thaw cycles in the moist chamber.

Figure 18 (a and b) shows the hydration level of the concrete specimens at 28, 90 and 365 days. It can be observed that at 365 days all specimens increase their hydration level. The hydration level reached by the $\mathrm{C} 45$ specimens is higher than the $\mathrm{C} 30$. This is because of the higher cement content $400 \mathrm{~kg} / \mathrm{m}^{3}$, compared with the $380 \mathrm{~kg} / \mathrm{m}^{3}$ of the C 30 .

As expected, it was also observed that at 28 days all the dry-cured specimens showed a lower hydration level than the moist cured specimens, with this difference being more notable for the $\mathrm{C} 45$ specimens. From these results it can be concluded that the moistcured specimens experienced a higher hydration rate than the dry- cured specimens. The hydration rate of
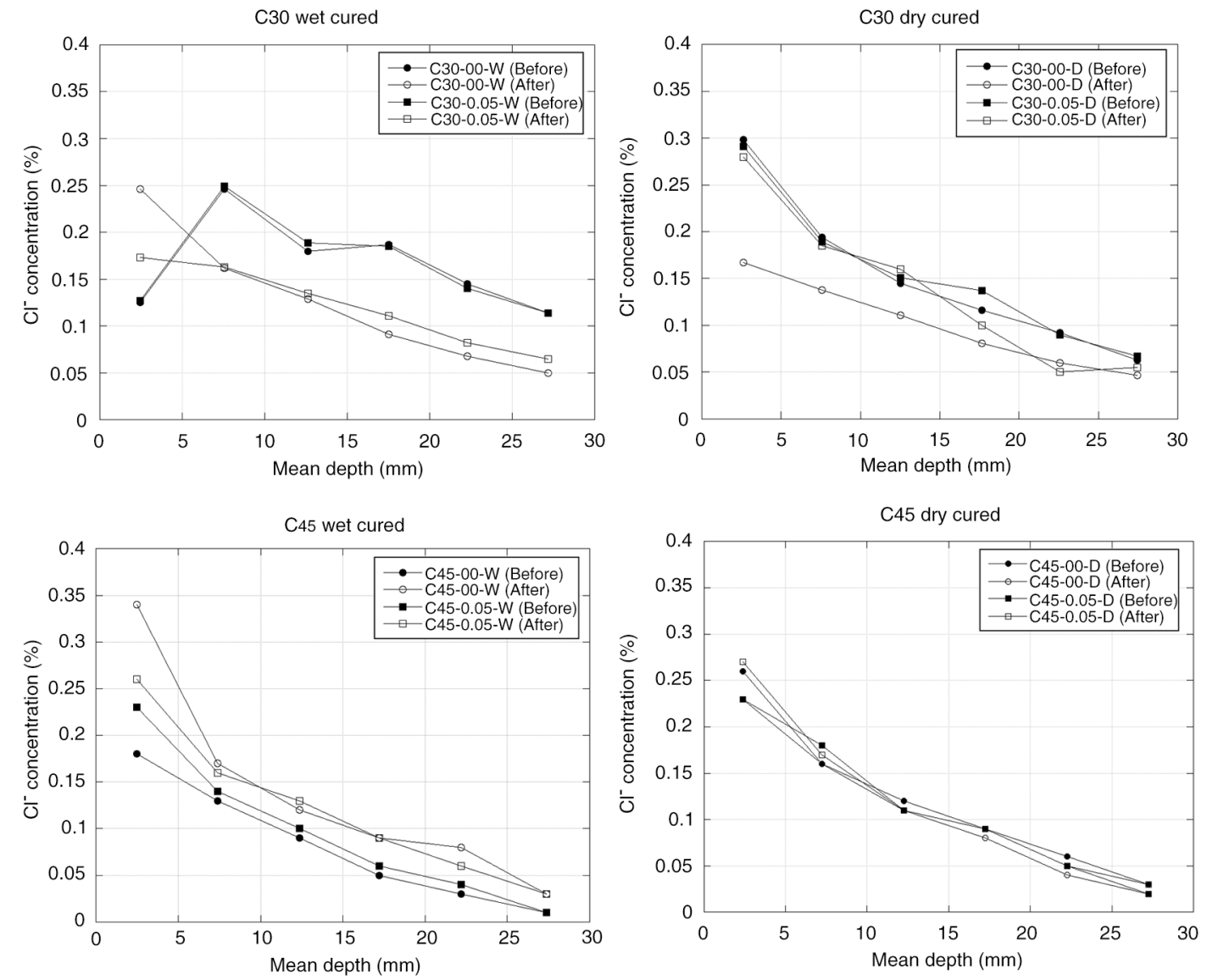

FIGURE 16. Chloride penetration profile for the four concretes (before and after freezing-thawing test). 


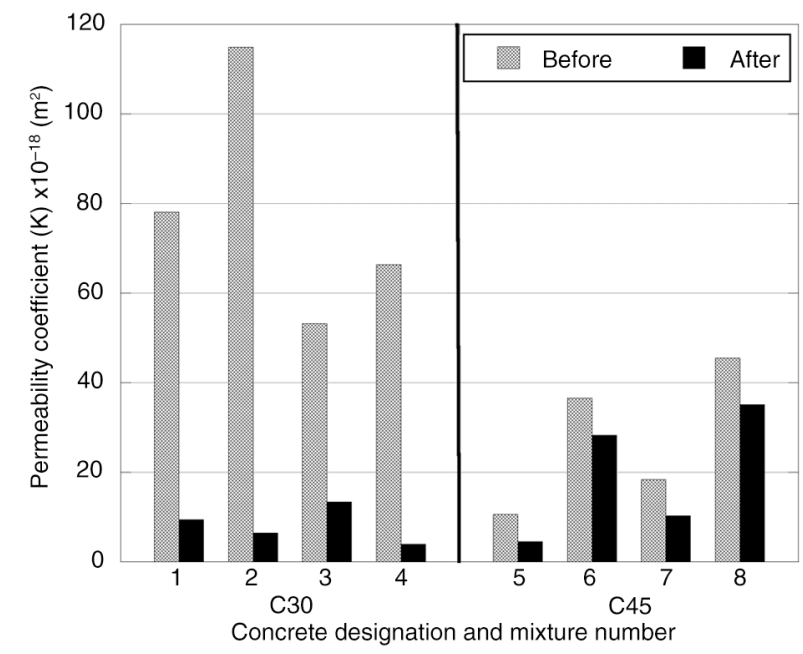

FIGURE 17. Apparent coefficient of oxygen permeability of concrete (before and after freezing-thawing test).
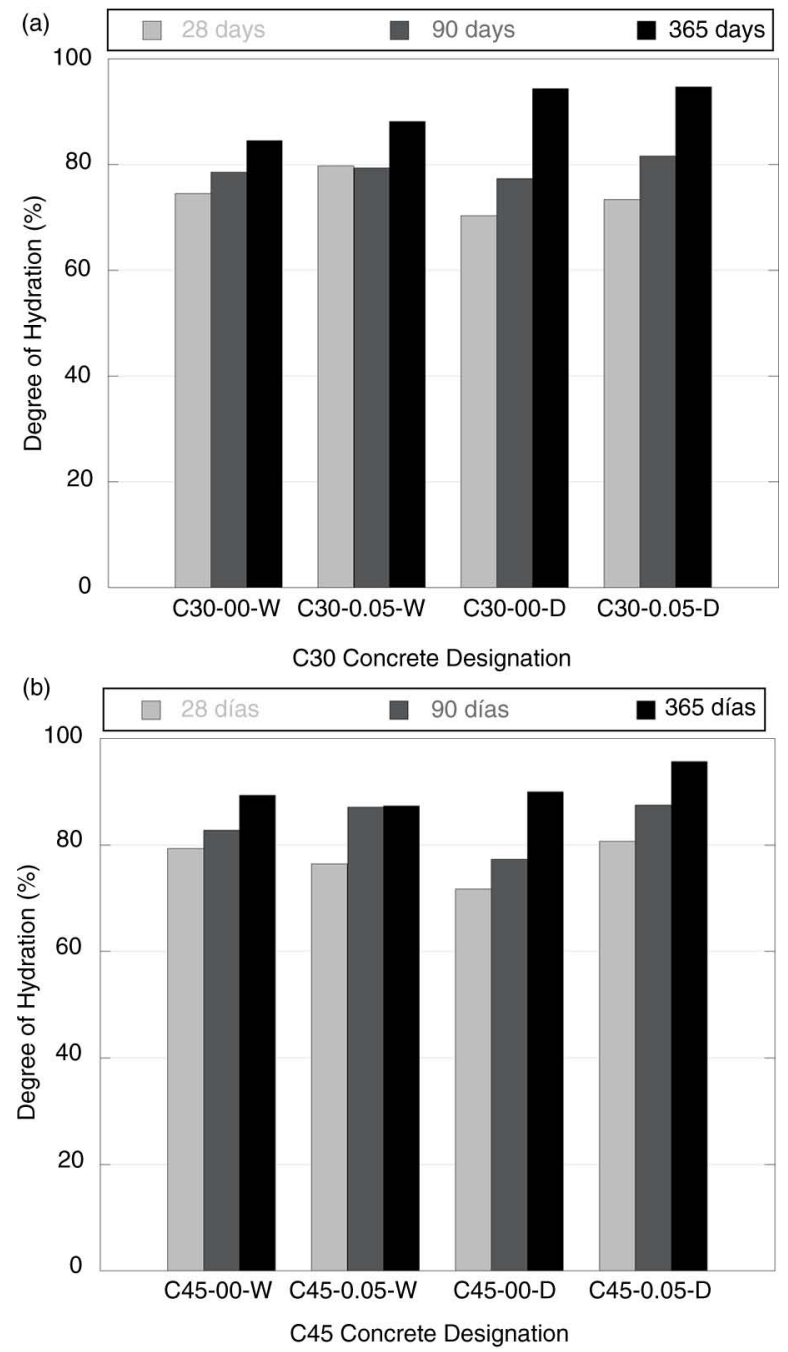

Figure 18. Degree of hydration of the cement of the concretes: a) C30, b) C45.
TABle 5. Porosity of the specimens at different depths after cycles

\begin{tabular}{lccccc}
\hline & \multicolumn{5}{c}{ Porosity (\%) After cycles } \\
\cline { 2 - 6 } & In & CIn & CEx & Ex & Mean \\
\hline Distance to center (cm) & 0 & 2.5 & 4.5 & 6.5 & \\
C30-00-W & 11.54 & 12.99 & 12.16 & 12.12 & $\mathbf{1 2 . 1 9}$ \\
C30-0.05-W & 15.84 & 12.28 & 14.32 & 14.88 & $\mathbf{1 4 . 3 3}$ \\
C30-00-D & 11.02 & 12.17 & 12.72 & 10.59 & $\mathbf{1 1 . 6 2}$ \\
C30-0.05-D & 16.88 & 14.08 & 14.58 & 14.33 & $\mathbf{1 4 . 9 7}$ \\
C45-00-W & 12.95 & 11.05 & 13.00 & 9.07 & $\mathbf{1 1 . 5 1}$ \\
C45-0.05-W & 20.56 & 17.70 & 20.19 & 15.53 & $\mathbf{1 9 . 0 0}$ \\
C45-00-D & 10.15 & 10.39 & 9.00 & 9.06 & $\mathbf{9 . 6 5}$ \\
C45-0.05-D & 14.74 & 15.53 & 16.89 & 14.06 & $\mathbf{1 5 . 3 0}$
\end{tabular}

the dry-cured specimens was slower, resulting in more accessible pore space to the moist movement and improvements in the concrete freeze-thaw resistance. This coincides with the higher pore percentage in dry-cured specimens, especially in the case of the C30. This tendency was maintained also at 90 days, though with less pronounced differences. At 365 days, the duration that the specimens were maintained in the climatic chamber, all the specimens cured at extreme conditions reached higher hydration levels than the specimens that were wet during the first week.

This surprising result, under which concrete under dry-curing conditions improves its behaviour after freeze-thaw cycles, should be treated with caution. The accelerated test in a climatic chamber leads to completion of the hydration process of the bad-cured concrete explains the reason for the improvement of the concrete behaviour. Obviously, a well-cured concrete with an air-entrainment agent should be the best solution against the freeze-thaw cycle and scaling behaviour of concrete. In the practical case of in situ concrete, with a bad curing process, shrinkage cracking will appear and the microstructure will be more porous, with both being detrimental to the freezing-thawing behaviour.

Table 6 shows the measured values of water gel, portlandite content and degree of hydration, before and after cycles, at four distances from the
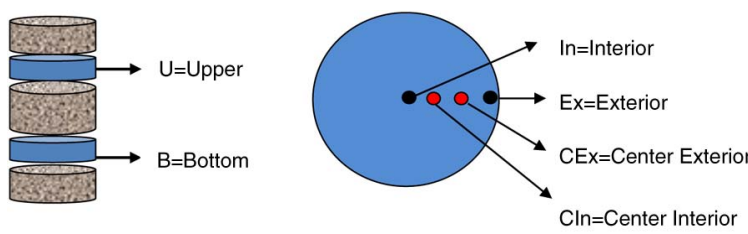

FIGURE 19. Sketch of the points of assessment in the specimen of the porosity, water gel, portlandite content and degree of hydration. 
TABLE 6. Water gel, portlandite content and hydration degree of the C-30 specimens before and after cycles

\begin{tabular}{|c|c|c|c|c|c|}
\hline \multirow{3}{*}{ C30-00-W } & \multicolumn{5}{|c|}{ Before cycles } \\
\hline & \multicolumn{5}{|c|}{ Upper slice } \\
\hline & In & CIn & CEx & $\mathbf{E x}$ & Mean \\
\hline Gel (\%) & 7.94 & 9.51 & 8.93 & 4.18 & 7.64 \\
\hline Portlandite water (\%) & 13.69 & 13.91 & 11.32 & 9.73 & 12.1625 \\
\hline Hydration degree (\%) & 81.84 & 86.67 & 83.59 & 65.14 & 79.31 \\
\hline \multirow{3}{*}{ C30-00-W } & \multicolumn{5}{|c|}{ After cycles } \\
\hline & \multicolumn{5}{|c|}{ Upper slice } \\
\hline & In & CIn & CEx & Ex & Mean \\
\hline Gel (\%) & 9.85 & 10.15 & 10.55 & 11.21 & 10.44 \\
\hline Portlandite water (\%) & 23.69 & 20.3 & 24.15 & 26.99 & 23.78 \\
\hline Hydration degree (\%) & 93.01 & 94.65 & 94.42 & 89.14 & 92.81 \\
\hline \multirow{3}{*}{ C30-00-D } & \multicolumn{5}{|c|}{ Before cycles } \\
\hline & \multicolumn{5}{|c|}{ Upper slice } \\
\hline & In & CIn & CEx & Ex & Mean \\
\hline Gel (\%) & 8.4 & 8.64 & 7.44 & 6.83 & 7.83 \\
\hline Portlandite water $(\%)$ & 15.81 & 14.29 & 15.24 & 14.69 & 15.01 \\
\hline Hydration degree (\%) & 79.97 & 77.54 & 78.75 & 71.53 & 76.95 \\
\hline \multirow{3}{*}{ C30-00-D } & \multicolumn{5}{|c|}{ After cycles } \\
\hline & \multicolumn{5}{|c|}{ Upper slice } \\
\hline & In & CIn & CEx & $\mathbf{E x}$ & Mean \\
\hline Gel (\%) & 8.59 & 11.16 & 8.11 & 10.14 & 9.5 \\
\hline Portlandite water $(\%)$ & 18.14 & 25.23 & 13.96 & 23.69 & 20.69 \\
\hline Hydration degree (\%) & 91.79 & 94 & 85.38 & 93.98 & 91.29 \\
\hline
\end{tabular}

surface (Figure 19) of the C30-00 specimens. In all cases, differencesin the water gel, portlandite content and degree of hydration values were found. Similar differences were found for the other concretes.

\section{STATISTICAL ANALYSIS OF RESULTS}

Given the large number of variables involved, a rigorous statistical analysis is essential for the correct interpretation of the above results. Logical differences appeared to be detected in the values of some of the properties in the two classes of concrete. The existence or otherwise of entrained air proved to be a determinant in concrete behaviour when exposed to freeze-thaw cycles. Specimen curing was apparently unrelated to such behaviour, although it did affect durability in a number of ways.

Some concrete properties (strength, for instance) may improve after freeze-thaw cycles as a result of the increase in age. Less favourable values would be an indication of physical damage induced by the cycles. Other properties may be unaffected by age but impacted by the mechanical effect of the freezing and thawing. Hence, the possible dependence among variables and their variation before and after the freeze-thaw cycles must be analysed.

The effect of the freeze-thaw cycles was determined by statistically analysing the data interdependence with SPSS software, pursuant to the following:

a) Variables related to concrete characteristics: curing, wet (1) or dry (2); entrained air content (0) (no air entraining admixture) or $0.5(0.5 \%$ of admixture by cement weight); and characteristic concrete strength (30 or $45 \mathrm{MPa})$. The result of the combination of variables is given in Table 7 .

All the above variables are categorical, that is to say, each group accounts for $50 \%$ of the data for each variable. This must be taken into account in statistical analysis of the data.

b) Variables related to the mechanical damage induced by the freeze-thaw cycles: variation in compressive strength, modulus of elasticity, tensile strength and Poisson's ratio. 
TABLE 7. Combination of variables for statistical analysis related to concrete type

\begin{tabular}{lccc}
\hline Mixture & Strength (MPa) & $\begin{array}{c}\text { Wet-cured (1) } \\
\text { Dry-cured (2) }\end{array}$ & $\begin{array}{c}\text { Air entrainment } \\
\text { agent (\%) }\end{array}$ \\
\hline 1 & & 1 & 0 \\
2 & 30 & & 0.5 \\
3 & & 2 & 0 \\
4 & & 0.5 \\
5 & & 1 & 0 \\
6 & 45 & & 0.5 \\
7 & & 2 & 0 \\
8 & & & 0.5 \\
\hline
\end{tabular}

In all cases strength may have risen due to the increasing age of the samples, while a decline would indicate the existence of mechanical damage.

c) Variables related to durability: variation in the depth of water penetration, porosity and the chloride diffusion coefficient.

d) Variables related to monitoring-mediated damage detection: variation in the relative dynamic modulus of elasticity (RDME) measured with ultrasound, as well as in weight and length.

The value used in the last three groups of variables is the ratio between the post- and pre-cycle values.

Spearman's rank correlation coefficient was used to formulate the correlation matrix and analyse the possible correlation among variables, since the residues were non-standard. This non-parametric statistic can be used in such cases.

Table 8 shows the correlation matrix for all the found with this statistic, along with the levels of significance. A correlation was considered to be significant where the bilateral value was lower than 0.05 . Where the value was lower than 0.01 , the correlation was considered to be determinant $(43,44)$.

The following conclusions can be drawn from an analysis of the matrix:

- The concrete characteristic that most clearly signals the effect of freezing-thawing-induced damage is the presence of the air-entraining admixture, given that it is the only parameter significantly correlated with the variation in compressive strength.

- Since curing type and concrete category are not correlated with the damage caused by freeze-thaw cycles, they cannot be considered to affect the existence or otherwise of post-test damage.

- The post-freeze-thaw cycle variation in compressive and tensile strength is heavily dependent on the presence of the air-entraining admixture, making it a valid parameter for detecting and quantifying the freezing-thawing test results.

- The variation in the modulus of deformation is highly self-correlated with the variation in the Poisson ratio. Both parameters are closely correlated with the variation in compressive and tensile strength, though they exhibit no clear dependence on the existence of the airentraining admixture or the tests that quantify freezing-thawing-induced damage.

- The variables related to durability, namely the variation in porosity, the chloride diffusion coefficient and water penetration are unrelated to the presence of the air-entraining admixture, the damage quantifiers or concrete strength. Neither are they affected by curing conditions, though the results show that these conditions and concrete type impact the absolute durability value the freeze-thaw cycles do not differentially impact wet- and dry-cured concrete or concretes with different characteristic strength.

Post-cycle variation in compressive strength, with respect to the categorical variables representing concrete characteristics and curing conditions are analysed below, using error bars. These bars show the distribution of all the variations in the strength values in each group of the categorical variable (for example, with or without an air-entraining admixture), along with the mean value and the $95 \%$ confidence interval.

A mean value greater than 1 indicates that strength increased after the freeze-thaw cycles, due to the greater age of the specimens, and that no damage was caused. The opposite denotes cycle-induced damage. A small confidence interval reinforces the conclusions, given that it means that the group analysed played a primary role in mediating the damage, while the other variables had scant if any effect.

Figures 20 to 22 show strength loss versus the presence/absence of air-entraining admixture, wetand dry-curing and 30/45 MPa characteristic strength. The implications of these graphs are discussed below.

- Figure 20 reveals that the existence or otherwise of the air-entraining admixture categorically separated the results into two groups: with no admixture the mean was lower than 1, indicating the existence of damage, and the confidence interval was wide (this denoted the possible secondary effect of other variables in this case). With the admixture, the mean was clearly higher than 1 , with a narrow confidence interval, revealing a lack of damage and the non-intervention of other variables when the admixture was present. Consequently, this categorical division was highly significant, statistically speaking, and the presence of the air-entraining admixture 
TABLE 8. Correlation matrix for variation in concrete properties (1)

\begin{tabular}{|c|c|c|c|c|c|c|c|c|c|c|}
\hline & $f_{c}$ & $f_{c t}$ & $E$ & $v$ & $\begin{array}{c}\text { MIP } \\
\text { porosity }\end{array}$ & $\begin{array}{c}\text { Depth water } \\
\text { penetration }\end{array}$ & $\begin{array}{c}\text { Chloride diffusion } \\
\text { coefficient }\end{array}$ & $\begin{array}{c}\text { Characteristic } \\
\text { compressive strength }\end{array}$ & $\begin{array}{c}\text { Curing } \\
\text { type }\end{array}$ & $\begin{array}{l}\text { Air entrainment } \\
\text { admixture }\end{array}$ \\
\hline \multirow[t]{2}{*}{$f_{c}$} & 1 & $0.764\left(^{*}\right)$ & $0.868(* *)$ & $0.883(* *)$ & -0.411 & -0.583 & -0.030 & 0.321 & 0.185 & $0.765\left(^{*}\right)$ \\
\hline & & 0.027 & 0.005 & 0.004 & 0.311 & 0.129 & 0.944 & 0.438 & 0.661 & 0.027 \\
\hline \multirow[t]{2}{*}{$f_{c t}$} & $0.764(*)$ & 1 & $0.769\left(^{*}\right)$ & $0.759\left(^{*}\right)$ & -0.168 & -0.571 & 0.456 & 0.518 & 0.147 & $0.799\left(^{*}\right)$ \\
\hline & 0.027 & & 0.026 & 0.029 & 0.692 & 0.140 & 0.256 & 0.189 & 0.728 & 0.017 \\
\hline \multirow[t]{2}{*}{ E } & $0.868(* *)$ & $0.769\left(^{*}\right)$ & 1 & $0.977(* *)$ & -0.698 & -0.681 & 0.178 & 0.498 & 0.386 & 0.563 \\
\hline & 0.005 & 0.026 & & 0.000 & 0.054 & 0.063 & 0.674 & 0.209 & 0.345 & 0.147 \\
\hline \multirow[t]{2}{*}{$v$} & $0.883(* *)$ & $0.759\left(^{*}\right)$ & $0.977(* *)$ & 1 & -0.640 & -0.592 & 0.175 & 0.432 & 0.419 & 0.563 \\
\hline & 0.004 & 0.029 & 0.000 & & 0.087 & 0.122 & 0.678 & 0.285 & 0.302 & 0.146 \\
\hline \multirow[t]{2}{*}{ MIP porosity } & -0.411 & -0.168 & -0.698 & -0.640 & 1 & 0.691 & 0.036 & -0.445 & -0.588 & 0.125 \\
\hline & 0.311 & 0.692 & 0.054 & 0.087 & & 0.058 & 0.932 & 0.269 & 0.125 & 0.769 \\
\hline \multirow[t]{2}{*}{ Depth water penetration } & -0.583 & -0.571 & -0.681 & -0.592 & 0.691 & 1 & -0.085 & -0.616 & -0.509 & -0.290 \\
\hline & 0.129 & 0.140 & 0.063 & 0.122 & 0.058 & & 0.842 & 0.104 & 0.198 & 0.486 \\
\hline \multirow{2}{*}{$\begin{array}{l}\text { Chloride diffusion } \\
\text { coefficient }\end{array}$} & -0.030 & 0.456 & 0.178 & 0.175 & 0.036 & -0.085 & 1 & $0.708\left(^{*}\right)$ & -0.240 & -0.053 \\
\hline & 0.944 & 0.256 & 0.674 & 0.678 & 0.932 & 0.842 & & 0.050 & 0.566 & 0.900 \\
\hline \multirow{2}{*}{$\begin{array}{l}\text { Characteristic compressive } \\
\text { strength }\end{array}$} & 0.321 & 0.518 & 0.498 & 0.432 & -0.445 & -0.616 & $0.708\left(^{*}\right)$ & 1 & 0.000 & 0.000 \\
\hline & 0.438 & 0.189 & 0.209 & 0.285 & 0.269 & 0.104 & 0.050 & & 1.000 & 1.000 \\
\hline \multirow[t]{2}{*}{ Curing type } & 0.185 & 0.147 & 0.386 & 0.419 & -0.588 & -0.509 & -0.240 & 0.000 & 1 & 0.000 \\
\hline & 0.661 & 0.728 & 0.345 & 0.302 & 0.125 & 0.198 & 0.566 & 1.000 & & 1.000 \\
\hline \multirow[t]{2}{*}{ Air entrainment admixture } & $0.765\left(^{*}\right)$ & $0.799(*)$ & 0.563 & 0.563 & 0.125 & -0.290 & -0.053 & 0.000 & 0.000 & 1 \\
\hline & 0.027 & 0.017 & 0.147 & 0.146 & 0.769 & 0.486 & 0.900 & 1.000 & 1.000 & \\
\hline
\end{tabular}

(1) The text values shown are the post-cycle/pre-cycle ratios.

The first value in each cell is the correlation coefficient and the second the (bilateral) significance level.

$\left(^{*}\right)$ The correlation is significant at 0.05 .

(**) The correlation is significant at 0.01 


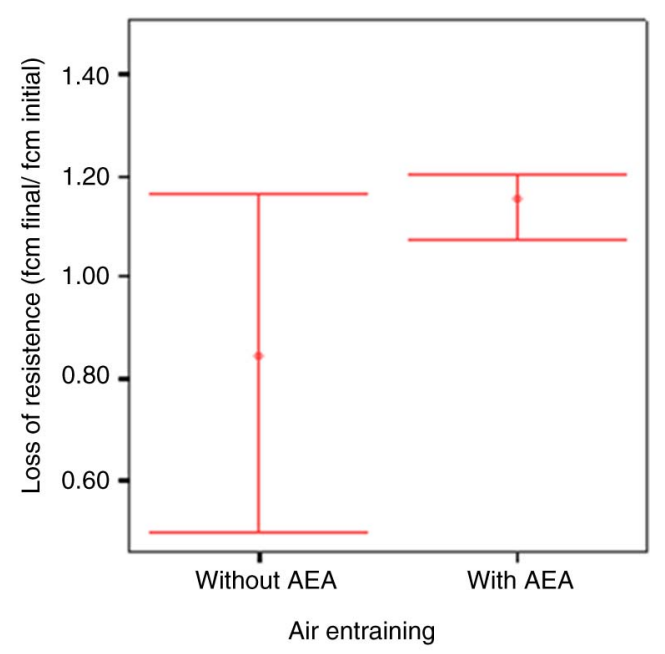

FIGURE 20. Graph of error-bar at 95\% confidence for concrete with and without air-entraining.

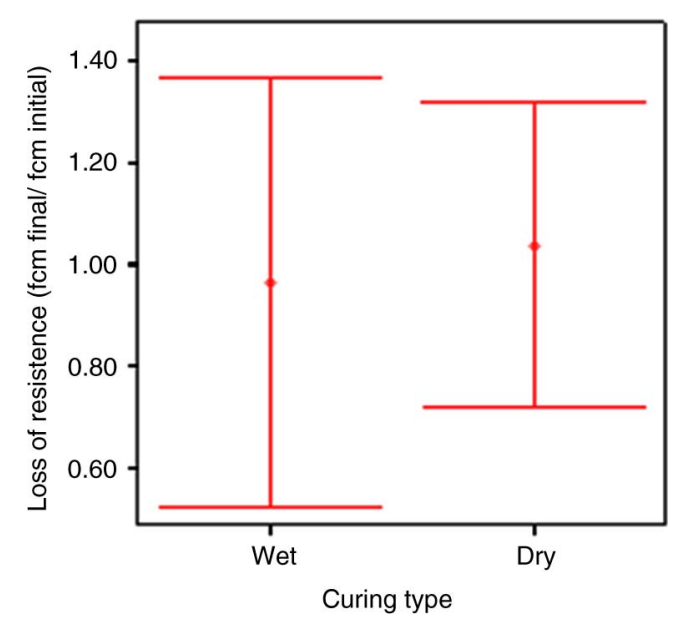

FiguRE 21. Graph of error-bar at $95 \%$ confidence depending on the curing type.

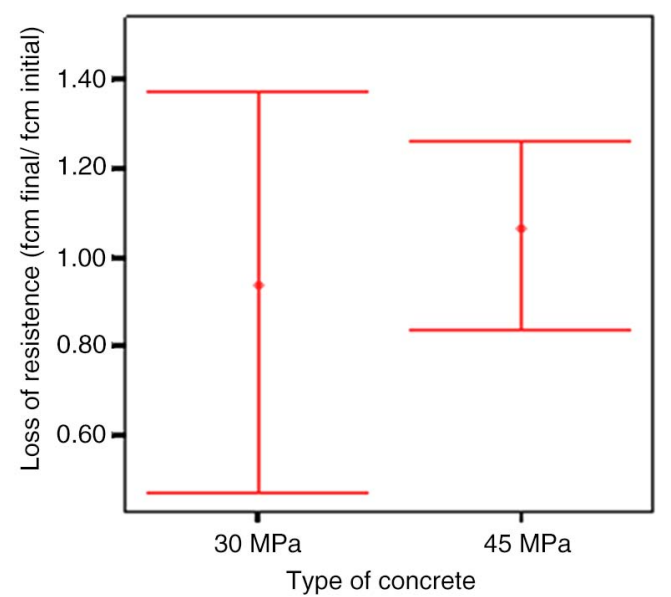

Figure 22. Graph of error-bar at $95 \%$ confidence depending on the type of concrete. was obviously instrumental in the existence or otherwise of post-freezing-thawing damage.

- Figure 21 shows the results for wet- and drycuring categories. Applying similar reasoning, it appears to show that dry-cured specimens were more resistant to freezing-thawing, in terms of both the mean value and the confidence interval. Here the much wider confidence values denoted the relevance of other variables. A possible explanation for these observations is associated with the greater porosity of dry-cured concretes, which would mitigate the freezing-thawing process in much the same way as entrained air.

- In an analogous sense, according to Figure 22 better performance was observed in the 45-MPa concrete. This was also reflected in both the mean value found for the categorical group and the breadth of the confidence interval. The covariance analysis revealed no significant dependence between strength loss and characteristic strength. Although the population study denoted such dependence, it was much less intense than that observed for the presence or absence of the air-entraining admixture.

\section{CONCLUSIONS}

The specimens without an air-entraining agent experience generalised deterioration of the mechanical properties as a result of the freezingthawing test. The specimens with an air-entraining agent are more resistant to the freeze-thaw cycles than those without the air-entraining agent. The statistical study confirmed the test results to the effect that the sole concrete property with a determining effect on its freeze-thaw resistance involved the presence or absence of an air-entraining admixture. The RDME evolution and durability factor seem to be a useful and precise technique to detect the freezing-thawing deterioration at early ages.

Concrete quality and curing conditions appeared to have a slight effect on concrete freezing-thawing performance, which was higher in dry- than wetcured specimens and higher in $45-$ than in $30-\mathrm{MPa}$ concrete. This was detected in the population study in both cases, for no significant correlation was observed between these variables and compressive strength loss.

Even though the statistical analysis concludes that the main affecting parameter to freeze-thaw resistance is the presence or absence of an airentraining admixture, some additional conclusions may be obtained from the experimental results:

- The durability characteristics of concrete exposed to freeze-thaw cycles are related to its pore microstructure. The pore volume, radius and 
size distribution determine the freezing point of the pore solution and the quantity of ice formed in the pores. It seems that the pore volume and pore size are larger before the freeze-thaw cycles. This is because the hydration of the cement continued during the freezing-thawing test, as it has developed insufficiently during the curing period due to its extreme conditions.

- The hydration level of the specimens before the freeze-thaw cycles was approximately $10 \%$ lower in the moist-cured specimens and approximately 24\% lower in the dry-cured specimens. These results coincide with the pore volume and size results, which were higher before the freeze-thaw cycles. At the end of the cycles, the hydration of the cement, which developed insufficiently during the curing process due to the low humidity and high curing temperature, was completed.

- In general, both curing conditions permitted the continuation of the hydration process and the strengthening of the transition zone between the gravel and paste during the freeze-thaw cycles. The wetting of the specimens further enhanced the hydration process, resulting in a closer pore structure. In contrast, the unwetted specimens resulted in a more open pore structure, with more interconnected pores, which served as beneficial for freeze-thaw resistance.

- Considering concrete with a water/cement ratio of 0.5 and applied conditions of $37 \%$ relative humidity and $30{ }^{\circ} \mathrm{C}$ temperature, the type of curing - with or without daily wetting during the first week - does not appear to be a significant variable in the deterioration due to freezethaw cycles. In certain cases, there was even an improvement in the freeze-thaw resistance of the dry-cured specimens.

- The results of the standard ASTM C 666 (28) should be treated carefully when applied to early-age concretes. Saturated concrete specimens under freeze-thaw cycles may complete the hydration process, leading to erroneous interpretations when extended to the in situ concrete under unsaturated conditions.

\section{ACKNOWLEDGEMENTS}

The authors gratefully acknowledge the financial support for the research provided by the Spanish Ministerio de Economía y Competitividad under grant DPI-2011-24876.

\section{REFERENCES}

1. Medina, M.; de Rojas, I.; Frias, M. (2013) Freeze-thaw durability of recycled concrete containing ceramic aggregate. Journal of Cleaner Production, 40, 151-160. http://dx.doi. org/10.1016/j.jclepro.2012.08.042.
2. Richardson, E.; Coventry, K.A.; Wilkinson, S. (2012). Freeze/ thaw durability of concrete with synthetic fibre additions. Cold Regions Science and Technology, 83-84, 49-56. http:// dx.doi.org/10.1016/j.coldregions.2012.06.006.

3. Haitao, Y.; Shizhu, T. (2015) Preparation and properties of high-strength recycled concrete in cold areas. Mater. Construcc. 65 [318], e050. http://dx.doi.org/10.3989/mc.2015.03214.

4. Enfedaque, A.; Romero, H.L.; Gálvez, J.C. (2014).Fracture energy evolution of two concretes resistant to the action of freeze-thaw cycles. Mater. Construcc. 64 [313], e005. http:// dx.doi.org/10.3989/mc.2014.00813.

5. Valenza, J.; Scherer, G.W. (2007) A review of salt scaling: I. Phenomenology. Cement and Concrete Research, 37, 1007-1021. http://dx.doi.org/10.1016/j.cemconres.2007.03.005.

6. Valenza, J.; Scherer, G. (2007) A review of salt scaling: II. Mechanisms. Cement and Concrete Research, 37, 1022-1034. http://dx.doi.org/10.1016/i.cemconres.2007.03.003.

7. Pigeon, M.; Marchand, J.; Pleau, R. (1996). Construction and Building Materials, 10, 339-348. http://dx.doi.org/ 10.1016/0950-0618(95)00067-4.

8. Li, W.; Pour-Ghaz, M.; Castro, J.; Weiss, J. (2012) Water Absorption and Critical Degree of Saturation Relating to Freeze-Thaw Damage in Concrete Pavement Joints. J. Mater. Civ. Eng. 24 [3], 299-307. http://dx.doi.org/10.1061/ (ASCE)MT.1943-5533.0000383.

9. Aguirre, A.M.; Mejía de Guriérrez, R. (2013) Durability of reinforced concrete exposed to aggressive conditions. Mater. Construcc. 63 [309], 7-38. http://dx.doi.org/10.3989/ mc.2013.00313.

10. Wu, Y.; Wu, B. (2014) Residual compressive strength and freeze-thaw resistance of ordinary concrete after high temperature. Construction and Building Materials, 54, 596-604. http://dx.doi.org/10.1016/j.conbuildmat.2013.12.089.

11. Yi, S.T.; Pae, S.W.; Kim, J.K. (2011) Minimum curing time prediction of early-age concrete to prevent frost damage. Construction and Building Materials, 25, 1439-1449.

12. Auskern, A.B.; Horn, W.H. (1976) Effect of curing conditions on the capillary porosity of hardened portland cement pastes. Journal of the American Ceramic Society, 59, 29-33. http://dx.doi.org/10.1111/j.1151-2916.1976.tb09380.x.

13. Sun, Z: Scherer, G.W. (2010) Effect of air voids on salt scaling and internal freezing. Cement and Concrete Research, 40, 260-270. http://dx.doi.org/10.1016/j.cemconres.2009.09.027.

14. Shang, H-S.; Yi, T-H. (2013) Freeze-Thaw Durability of Air-Entrained Concrete. The Scientific World Journal, 2013, Article ID 650791, 6 pages, http://dx.doi.org/10.1155/ 2013/650791.

15. Klieger, P.; Gebler, S.H. (1987) Fly ash and concrete durability. ACI Special Publication SP-100 (ed. J. Scanlon), 1043-1069.

16. Afrani, C.; Rogers, C. (1993) The effect of different cementing materials and curing regimes on the scaling resistance of concrete. In: Third Canadian Symposium on Cement and Concrete, 149-166.

17. Bilodeau, A.; Carette, G.G.; Malhotra, V.M.; Langley, W.S. (1993) Influence of curing and drying on the salt scaling resistance of fly ash concrete. ACI Special Publication SP-126 (ed. VM Malhotra), 201-228.

18. Langlois, M.; Beaupré, D.; Pigeon, M.; Foy, C. (1989) The influence of curing on salt scaling resistance of concrete with and without silica fume. ACI Special Publication SP-114 (ed. VM Malhotra), 971-990.

19. Neville, A.M. (1995) Properties of concrete. Longman Scientific \& Technical. UK.

20. Escalante-García, J.I.; Sharp, J.H. (2001) The microstructure and mechanical properties of blended cements hydrated at various temperatures. Cement and Concrete Research, 31, 695-702. http://dx.doi.org/10.1016/S0008-8846(01)00471-9.'

21. Kjellsen, K.O.; Detwiler, R.J.; Gjorv, O.E. (1991) Development of microstructures in plain cement pastes hydrated at different temperatures. Cement Concrete Research, 21, 179-189. http://dx.doi.org/10.1016/0008-8846(91)90044-I.

22. Kjellsen, K.O.; Detwiler, R.J.; Gjorv, O.E. (1990) Pore structure of plain cement pastes hydrated at different temperatures. Cement Concrete Research, 20, 927-933. 
23. Price, W.H. (1951) Factors influencing concrete strength. ACI Journal, 47, 417-432.

24. Copeland, L.E.; Kantro, D.L. (1969) Hydration of Portland cement. In: Proc. Int. Symp. Chem. Cem., Tokyo, 387-421.

25. Khurana, R.; Torresan, I. (1997) New admixtures for eliminating steam curing and its negative effects on durability. ACI Special Publication SP-173, 83-103.

26. Jacobsen, S.; Saether, D.H.; Sellevold, E.J. (1997) Frost testing of high strength concrete: frost/salt scaling at different cooling rates. Materials and Structures, 30, 33-42. http://dx.doi.org/10.1007/BF02498738.

27. Jonsson, J.A.; Olek, J. (2004) Effect of temperaturematch-curing on freeze-thaw and scaling resistance of high-strength concrete. Cement, Concrete and Aggregates. ASTM International, 26, 21-25. http://dx.doi.org/10.1520/ CCA11911.

28. ASTM C666/C 666M-03 (2008). Standard Test Method for Resistance of Concrete to Rapid Freezing and Thawing. ASTM International, vol. 4.02, 341-346.

29. Zhang, J.; Taylor, P. (2014) Pore Size Distribution in Cement Pastes in Relation to Freeze-Thaw Distress. Journal of Materials in Civil Engineering, http://dx.doi.org/10.1061/ (ASCE)MT.1943-5533.0001053

30. EHE-08 (2008), Structural Concrete Spanish Code, (in Spanish), Ministerio Fomento, Spain.

31. EN 12390-3 (2003) Testing hardened concrete, Part 3: compressive strength of test specimens, AENOR, Spain.

32. UNE 12390-13 (2014) Concrete tests. Determination of secant modulus of elasticity in compression, AENOR, Spain.

33. EN 12390-6 (2005) Testing hardened concrete, Part 6: tensile splitting strength of test specimens, AENOR, Spain.
34. ASTM D4404 (2004) Standard test for determination of pore volume distribution of soil and rock by MIP, ASTM International.

35. RILEM- TC 116-PCD (1999) Permeability of concrete as a criterion of its durability, Materials \& Structures, 32, 174-178.

36. Kollej, J.J. (1989) The determination of the permeability of concrete to oxygen by Cembureau method-a recommendation. Materials \& Structures, 22, 225-230. http://dx.doi. org/10.1007/BF02472192.

37. ASTM C1543 (2002) Standard test for determination the penetration chloride ion concrete by ponding, ASTM International.

38. UNE 112010 (1994) Assembly corrosion. Chloride determination for in service concrete. AENOR, Spain.

39. EN 12390-8 (2009) Testing hardened concrete, Part 8: depth of penetration of water under pressure, AENOR, Spain.

40. ASTM E1131 (2008) Standard Test Method for Compositional Analysis by Thermogravimetry, ASTM International.

41. ASTM C 143 (2010) Standard Test Method for Slump of Hydraulic-Cement Concrete. ASTM International.

42. Zhao, J.; Caib, G.; Gao, D.; Zhao, S. (2014) Influences of freeze-thaw cycle and curing time on chloride ion penetration resistance of Sulphoaluminate cement concrete. Construction and Building Materials, 53, 305-311. http:// dx.doi.org/10.1016/j.conbuildmat.2013.11.110

43. Belia, S.; Fidler, F.; Willams, J.; Cumming, G. (2005) Researchers misunderstand confidence intervals and standard error bars, Psychological Method, 10 [4], 389-396. http://dx.doi.org/10.1037/1082-989X.10.4.389.

44. Masson, M.E.; Loftus, G.R. (2003) Using confidence intervals for graphically based data interpretation, Canadian Journal of Experimental Psychology, 57 [3], 203-220. http:// dx.doi.org/10.1037/h0087426. 